\title{
Interpersonal Communication in Social Networking Sites: An Investigation in the Framework of Uses and Gratification Theory
}

\author{
Aysen Temel Eginli, Ege University, Turkey \\ Neslihan Ozmelek Tas, Ege University, Turkey
}

\begin{abstract}
In the twenty-first century, thanks to the development of information and communication technologies that, communication possibilities between people is getting unlimited. People can reach and follow anyone as whenever they want. Especially, after the development of web 2.0 which ensures interactive communication, social media has become much dominant in people's lives. The social media is valuable for people to create social networks and sustain their relations, also protects the communication between them. Therefore, it has a fundamental place in people's lives. Renckstorf and his friends (1996) evaluated the media usage of the people in the base of social interaction, and they created the model which is named Media Use as Social Action/MASA. The MASA model clarifies the people's media usage as a social movement. In addition, according to MASA, people use the media for their self-wants and self-needs. In this regard, people use the media for interpersonal communication purposes in four ways. These purposes are, getting information, doing cooperation, having relation, expressing and explaining and strategical use (Petric et al. 2011). In this work, people's aim of the using social media, especially for the aim of interpersonal communication, is explained in the base of theories. Also, in this paper, the results are evaluated that obtained from structured interviews based on the classification of MASA model, and thus, it is aimed to clarify which communication purposes do the people use the social network sites. When the results of research are evaluated in terms of Uses and Gratification theory which concerns on what people do with the media more than the effect of media on people, users of social network sites indicate that social network sites are characterized by informational-cooperative, relational-socialization, expressive, strategic, and four-dimensionality, but are responsive to the need for a large number of interpersonal communication.
\end{abstract}

Keywords: Social media, social network, social network sites, interpersonal communication, Uses and Gratification Theory. 


\section{Introduction}

People sit in the café together, but they are connected thousands of different people instead of each other, the fingertip of them is on the pages of social media continuously that they reach by using their phones. Even the first sentences of the individuals are like these" add me on Facebook, follow me on Twitter, did you see my photo on Instagram? Social network sites are so integrated to life that even it can be said that it is indispensable for individual's life. So, do the network sites create a new type of communication? Or, can it be evaluated that interpersonal communication is moving to a different dimension?

Thanks to the development of the technology of Web 2.0, the Internet has gained the specification of interactivity, so a new social platform has emerged that people can communicate with mass. This situation caused that interpersonal communication/interaction has been moved to the online environment. In addition, social Networks which is shaped by communication technologies has been emerged into the individuals' daily life as a new component of interpersonal communication. The amount of communication between people who can not interact in their daily life has increased owing to the virtual environments.

Van Dijk (2006) describes the 21st century as a network age. Also, he states the networks are just like a nervous system because they not only enter and affect people's social and personal life but also, they create roads for transporting the old friendships and the goods that they have. In this respect, he describes it with the term"information highway". In addition to this, he mentioned that there are both opportunities and risks just as if every infrastructure has.

In this case, communication has gained a timeless and spaceless specification. Therefore people can interact with each other continuously. Thanks to this kind of facilities, people have different ways to sustain and develop their social relations, so the structure of society and the way of communication has been affected directly. The notion of network sociality is merged depending on this. "In network sociality, social relations are not narrational, but informational; they are not based on mutual experience or common history, but primarily on the exchange of data and on catching up" (Wittel, 2001:51). 
According to "The rise of network society" book of Castells (2010), new communication technologies ensure the communication that is organized by Networks, and virtuality is a fundamental dimension of our reality. Levinson (2009) defines this era as being "new new media" and he clarifies the most significant feature of the era with the statement "every consumer is a producer". From this point of view, the content of media is produced and published by the same consumer of its. Therefore, it does not need to be created for academic purposes or does not need to be professional. Levinson (2009), stated another important feature of this era that having social character, also according to him, the new new media has uncovered new types of communication, and it ensures the development of new societies or the new media has the qualification to communicate between the certain cultures.

In this perspective, it can be seen that the studies mostly have been concentrated on the questions of "How do the messages transfer to the audience in the most effective way", "What can be done for the gratification of the audience?" and "Uses and gratifications examine what people do with the media rather than what media do to the people" (Blumler \& Katz, 1974).

\section{Literature Review}

\section{The Focus of the 21st century: Social Network Sites}

In the 21 st century, the development of web technologies has brought along unlimited and timeless communication. The focus of this is to communicate by using network sites. At this point, the terms like "social media, social network, social network sites, social-networking sites, online social networking" are used to define the communication which is mentioned, even they are being used instead of each other. Explaining these notions that are also used as an online communication environment, will ensure their proper usage.

The social media is defined as "a group of Internet-based applications that build on the ideological and technical foundations of Web 2.0 and that allow the creation and exchange of user-generated content" (Kaplan \& Haenlein, 2010: 61). Collin et.al. (2011: 8) define the notion of social media "is generally uses to describe collaborative media creation and sharing on a fairly large-scale (that can include SNS but also other participatory media activities such as news blogs) but can be extended to include smaller user-generated content network for 
micro-communities and things that sometimes fall outside SNS such as blogs/vlogs, podcasts, wikis, game modding.

Ellison et al. (2007) define the concept of social network as communication networks that enable to organize business relations, to establish new relationships, to get together with people who have common interests (such as music). Ellison and Boyd (2013: 154) describe the social network concept as "the collection of social relations of varying strength and importance that a person maintains", indicating that it is more appropriate to use the social network site concept instead of the social network concept. Boyd and Ellison (2008:211) define social network sites notion "as a web-based services that allow individuals to (1) construct a public or semi-public profile within a bounded system, (2) articulate a list of other users with whom they share a connection, and (3) view and traverse their list of connection and those made by others within the system". Social network sites and social-networking sites can be used with the same meaning and substitute for each other. Networking often refers to the beginning of relationships among strangers, while social networking refers to communication on sites (Boyd and Ellison, 2008: 211). Tong et al. (2008) define the concept of online social networking as a form that provides new relationships to its users or members, enabling them to maintain existing relationships and create impressions.

In this study, social network expression is used due to its qualifications such as, to maintain the relations which already exist in the online environment and to establish new relationships, to reach each other through a friend list, to create links between users and share in a system.

Social network sites have emerged as a school-based at the end of the 90s; then they immediately spread out by joining from all ages. Social network sites have become preferable than other communication tools like E-mail or chat rooms; even the users so much trust these networks that they can share their the most private information or photos in this environment. Even the information which is shared by users within their profile/account, there is a risk because, they share all kind of information about themselves (Henson et al. ,2011: 254-255). On social network sites, communication can be formed in a different way or about very different topics comparing with daily life. People can not just only discuss personal subjects, but also can talk about the public issues. They ensure these facilities to people (Li, 2011:562): 
- Blogging: people can upload photographs, text, etc.. Also they can share these as chronologically, and others can give feedback.

- Grouping: Users can join groups which are based on various topics.

- Networking: Users can communicate with their friends, and they can make new friends.

- Instant Messaging: Users can send messages and take feedback from their friends.

While considering the functions of social network sites, it can be seen that there are many positive contributions regarding people and especially the interpersonal communication, as well as negative effects. The most basic feature of social networking sites is to ensure interpersonal communication, or in other words, to allow face-to-face communication in a virtual environment. The use of these networks for the purpose of maintaining or dating old friendships by a person, reveals the socialization features of social networking sites (Eke et al.2014). Besides, social network sites have the social networking characteristics because they enable to establish new friendships, to meet people who have common interests, even access to people that they can not reach in the daily life. Another feature of social network sites is being a social navigation. The meaning of Social navigation feature is a person can connect with his/her friends and thanks to them he/she can reach the resources, information or people that he/she needed (Thelwall, 2009).

Collins et. al. (2011) explain the benefits of social network sites usage as "media literacy, formal educational outcomes, informal education and learning, creativity, individual identity and self-expression, strengthing social relationships, belonging and collective identity, building and strengthening communities, civic and political participation, self-efficacy and well-being”. Parks and Floyd (1996) have pointed out that interpersonal relationships have increased personalized communication and commitment characteristics, including wider and deeper interaction, interpersonal understanding and predictability, in their work on how to develop interpersonal relationships in online environments in their work "Making Friends in Cyberspace". Houghton (2012) has also mentioned that an interpersonal communication, which is established in the online environment, has a certainty feature, it increases the frequency of both passive and interactive communication. 
The ability of social network sites to provide continuous communication between people creates some problems in terms of both interpersonal communication and people. One of the most important problems is that people are getting worried about not being in the virtual environment and they can be worry about not renewing the information in the virtual environment. At the same time, the desire to communicate continuously in the virtual environment causes to not communicate in real life (Bala, 2014). According to AlKhaddam's (2013) research which has been carried out on the effect of social networks of interpersonal communication of university students that social network sites have a facilitating feature for gaining new contact, but they decrease the level of communication and interaction between the students and their families. In other words, because of constantly communicating with people in the virtual environment, people can have less time for contacting with their close relationships. At this point, it can be said that the communication in the real world are exchanging with the communication in the virtual world, and even the fake ones are shifting toward establishing communication and intimacy with the identities.

On the other hand, social networking sites (e.g., Facebook) consider as friends of all connected people, so allow others to comment on the person's page, to control the person's expressions, even allow the person to participate in the network environment. Even if there are weak links with many of the mentioned people who are friends on the Facebook, the sharing continues in this virtual environment, or these people, whom they know very little, are informed about their personal situation. In other words, the person loses control over his / her own private space in order to win friends. Most of the time, the information about the person can be spread to a large number of people very quickly. This is the "social convergence" feature of social networks (Boyd, 2008).

\section{Why people use social network sites: Uses and Gratification Theory}

When it is examined that the literature on the use of social media (related to the effects of the media), it appears that people explain it with four basic theories. These theories are Uses and Gratification Theory, Information Processing Theory, Social Identity Model, and Social Cognitive Theory. Information Processing Theory comes from the perspective of psychology and is based on the cognitive model of Richard Atkinson and Richard Shiffrin explaining "how the mind processes information" in 1968 (Beitzel, 2012). The theory basically describes the process of which a new person has spent time in his long memory, and it is also expressed 
that the communication of people with each other in relation to the use of social media is similar to the process of brain processing a new information and has the same effect. The Social Identity Model of Deindividuation Effects is a theory that explains how personal characteristics and differences can be reduced by developing anonymity in order to identify a person as a group member, and to increase the group salience and group cohesion with a computerized influence (Lee, 2004). Social Cognitive Theory, which is based on social learning theory, explains that one is influenced by affective, cognitive and biological events, behavioral patterns, in this sense, symbolic communication in social media also has the same process, helping to explain how online communication between people takes place and how relations are built (Bandura, 2001).

Uses and Gratifications Theory, one of the Early Mass Communication theories, characterizes the listener as active and motivated in the use of media. The focus of the theory is more about what people do with the media than what the media has on the person (Katz et al., 1974). From this point of view, the audience actively selects and uses the media according to their specific needs. The uses and gratification theory explains "how and why of media use". In this sense, when people use the media for specific purposes, they get a certain satisfaction from this use (Stafford et al., 2004). U\&G Theory is focused on five fundamental assumptions. The first one is, communication behavior is goal-directed and motivated. Secondly, the people are in an active position, while they are choosing the communication media which fulfill their needs. The third one is, people can define their communicational motives and gratifications. The fourth one is, media is focused on providing communication styles for paying attention, choosing and using. That's why there is a competition between tools of communication. The fifth one is that the people are affected by several social and psychological factors while they are choosing the communication alternatives (Flaherty et al., 1998: 252).

The basic assumption of the use and satisfaction approach is "medium as a source of influence within the context of other possible influences". At this point, the user is always active in selecting the desired medium (Byrant and Oliver, 2008). In other words, each user chooses different mediums to meet their different needs and acquires certain motives with this use. When it is evaluated in terms of social network sites, users of social network sites 
meet their different needs (e.g., having fun, communicating, acquiring information) by using social networks and they can be satisfied.

McLuhan (2016) explains the expression "The medium is the message" as determinative and controlling in the sense of medium's operational and practical fact. At this point, it is stated that the medium will be personal, social consequences and new technology will become the extension of each person. At this point, the power of medium or medium content for controlling and directing the people has reduced with the social network sites. Because people are no longer consuming the content of the medium passively, but they have become an active producer, that is the reason of decreasing.

The use of media by people is explained in two ways: on the basis of content (content gratifications) and on the basis of the experience of using media (process gratifications). When social media use is compared with traditional media use, it can be expressed that it gives more content satisfaction by creating more chance for communicating to the people (McGuire, 1974). In addition, in terms of usage and satisfaction theory, social media's main motivations can be regarded as allowing the person to learn social events related to daily life, staying in touch with his / her loved ones, getting away from daily life responsibilities and sharing a photo (Quan-Haase and Young, 2010).

Users of social network sites are satisfied with the meaning of social capital, communication, surveillance and social networking surfing because they face with a richer content compared to traditional media content (Joinson, 2008). As a result of the research which is belonged to Ellison et al. (2007) on Facebook's effects on social capital, it has been found that social gratifications are the motivating factor for people using Facebook, providing social ties to people and especially creating connections with friends in the past.

The vast majority of users of social network sites regard social media not only as an alternative communication medium but also as an expressional environment in which they can express their ideas and take ideas. However, another important reason why social network sites provide satisfaction for individuals is that information can be acquired immediately, and this can be done at the global level (Ngcongo, 2016: 16). 
Social media satisfies them much more than the traditional means of communication (Perse\&Courtright, 1993). Social network sites answer people's some needs, in other words, people use social media for many different aims, getting information, making relations and maintaining, configuring relations strategically, expressing themselves and clarifying. Whiting and Williams (2013) examined people social media usage including uses and gratifications theory and they present the aims of social media usage as; social interaction, information seeking, pass the time, entertainment, relaxation, communicatory utility, convenience utility.

Renckstorf et al. (1996) accept the people's use of media as a social movement and evaluating media use from the perspective of social interaction ) they have developed model as social movements the use of media (Media Use as Social Action / MASA MASA model identifies people's media usage as a social movement, according to MASA people use the media in accordance with their wishes and needs. In this sense, people use media for interpersonal communication purposes for four different purposes; Informational-cooperative, relational, expressive, strategic (Petric et al., 2011: 120-121):

- Informational-cooperative use: People get and give information, learn, dissemination information, joining business projects

- Relational use: Developing social relations, executing social norms, sustaining relations, gaining social support, making friends and maintaining them.

- $\quad$ Expressive use: People express themselves, personal experiences, wishes, belief, etc. Presenting İnternal communication, self-presentation and obtaining identity.

- Strategic use: People have conscious or unconscious their personal aims(controlling, organizing, entertaining, observing and watching, etc.) that they can realize by communication.

There is a direct relationship between interpersonal communication and media usage motives. By using social media, people can not only meet the interpersonal communication needs but also can answer their need of seeking companionship, alleviating boredom (Flaherty et al., 1998, 254). In this point, social media usage ensures three main interpersonal communication needs inclusion, affection, and control; such as acceptance by other people, like someone and someone likes you, having power over others and making them feel your power can fulfill interpersonal communication needs. (Ramirez et al., 2008). 
Social network sites give opportunity people to share information about themselves by creating accounts, and also thanks to these accounts by making comments and sharing they have a chance to express their own thoughts (Bateman et al., 2011). Having a place on social networks or in other words, investing in social networks assure people self-confidence through the principle of reciprocity. Thus, social networks make people who are interested in common things to get together, help to share information and get support. Obtaining mutual relations and sustaining these relations bring out emotional support, consequently, the quality of life has been improved. The relations which are set via social networks help users to know each other closely and get detailed information (Valenzuela et al., 2009: 877). The profile information of the person is the most important source of information for others to make impressions about him.). Person's Facebook profile is effective even when others have made a decision about his personality, and personality traits are evaluated on the profile (Bachrach, 2012).

From the perspective of Uncertainty Reduction Theory, the want of people learning about others is one of the fundamental aims of interpersonal communication. In the process of interpersonal communication, people want to reduce the uncertainty about the people they interact, and they want to know as much as they can or to guess (Gudykunst,1985). This situation directs people for seeking information about other people. Social networking sites provide clarity of the clues which is needed to provide social attraction and facilitate this with interactive features (Antheunis, et. al., 2008). In this mean, being a member of social networks ensures people to reduce the suspense and to have better relationships (Westerman, 2008: 753-754). Social networks encourage people to communicate online community. Owing to the online community, people identify themselves (self-defining) and get gratifications thus they can share about any topic they want. At the same time, being accepted and expressing yourself on these social networks motivates people for interpersonal interactions. The chance of socialization and gaining social status by joining groups which are held on social media makes communication sustained (Li, 2011:563). Rheingold (1993) pointed out in his "virtual community," book that people can come together who do not know each other thanks to the online network and they have an opportunity for establishing new relationships. In other words, "Social network is the component of social capital on the individual level (Brandtzæg, 2012: 467). 
According to Zhao (2006), connections that are created via social network creates offline relationships. Interpersonal communication becomes "corporeal co-presence" even it is not real-time communication and face to face in the relationships formed by social networks. In addition to this, the vital specification of social networks is a person can contact more than one person at the same time, and he/she can create interaction people in the same period. Moreover, it ensures continuous communication between people so that the weak bonds can get stronger as people know each other better.

As a result of the Mustafa and Hamzah's (2011) research "Usage of Online Social Networking in Malaysia"; through social networking sites, they have reached a conclusion that they are able to make wider friendships and easily manage friendships with friends from one place to another. In addition to this, they have indicated as the most important function of social network sites, talking with friends and groups, talking with active speakers and having fun. Mazman and Usluel (2011) have generally stated as a result of their work called "Gender Differences in Using Social Networks" that social networks are used to find an old school or colleagues, or even access those phone numbers or address information to reach them. When women are compared to men; social networks have been used by women to maintain existing relationships, to find and connect with old friends, and to use them for academic purposes, while men are using them to develop new relationships.

Social network sites that provide a wide variety of gratifications for people can also often cause negative effects. In his research titled "The Relationship between Frequency of Facebook Use, Participation in Facebook Activities, and Student Engagement" by Junco (2011), engagement describes the physical and psychological energy of the person, and in this sense examines the relationship between students' Facebook use and activities and engagement levels. As a result of his research, most of the psychological energies of the students have been spent on controlling their Facebook accounts and various Facebook activities. However, social media is an environment in which people feel the pressures of others as well as in their daily lives, and also it is an environment where independent thinking skills are influenced by others. The social network causes the person to become more open to the pressure of their friends. It is in the sense that one feels pressured because all likes or shares of people can be seen and are open to friends' comments. In this sense, social media 
causes the person to feel more powerful negative effects than face-to-face communication (Zeitel-Bank et al. 2014).

\section{A Research on Determining the Use of Social Network Sites for Interpersonal Communication Purposes}

\section{Research Method}

The purpose of the research is to determine the peoples' purpose of using social network sites and in particular for the interpersonal communication purposes. Through the research, it is aimed to evaluate the usage of the social network sites of people and their usage for interpersonal communication purposes in terms of uses and gratification. In this direction, research questions can be expressed as follows:

RQ1: For what purposes do people use social networking sites?

RQ2: For which interpersonal communication purposes do people use social-networking sites?

For this purpose, in-depth interviewing was chosen as a research method. In-depth interviewing is a qualitative research technique that involves conducting intensive individual interviews with a small number of respondents to explore their perspectives on a particular idea, program, or situation (Boyce and Palena, 2006). The in-depth interview is comprised all perspectives of the research topic, and mostly by using the open-ended questions, it helps to get detailed information. The face-to-face communication is the most important factor of this research method. Researchers can observe the participants, feelings, information, experiences. This research method has a common usage in social sciences such as journalism, law, business, and communication fields (Tekin, 2006:101).

In-depth interviewing has been conducted with 10 students who are studying at Ph.D. or master degree in Communication Faculty of Ege University. The participants consist of 4 female and 6 male students. The mean age of 10 participants was 28 years; range 25-30 years. Participants were chosen by using random sampling method. They were participated to research voluntarily. The approximate duration of interviews was 30 minutes. The in-depth interview guide was formed in the direction of MASA (Media Use as Social Action). The MASA model usually focuses on the phenomenology of mass media experiences (Renckstorf et al., 1996). The reason for the selection of the MASA model is that it guides the definition 
of a general typology for the use of media (Use of social networking sites) in interpersonal communication. In this sense, people use media for interpersonal communication purposes for four different purposes; Informational-cooperative, relational, expressive, strategic (Petric et al., 2011: 120-121):

The data obtained as a result of the interview were coded by two researchers and divided into groups. The codes of the two investigators were checked by another investigator. (The codes obtained as a result of the research are given in the table below). The codes obtained in the second phase were grouped according to the interpersonal communication objectives defined by the MASA model.

\section{Results of Research}

The codes which are generated in the direction of the data that obtained as a result of the investigation; Information, interaction / expressing, awareness/following, event, reaching, relationships. These six categories which are mentioned above had been grouped and interpreted based on MASA model in terms of usage purposes: informational-cooperative, relational, expressive, strategic

\section{- Informational-cooperative use:}

It is seen that social network sites meet the need of getting information and collaborating features of interpersonal communication, people get information, reach to information, get quick feedback, find the information which they want, be informed from others sharings by using social-networking sites. At the same time, according to all participants, they use social networking sites because both personal and public information spread so fast and it is easy to reach by social media. In this sense, some of the answers given by the participants are below. "Every day the thing what I turn-on is a computer, by using it, I can reach anything in seconds. On the other hand, go seller buy a newspaper, or I don't know... turn on the television, watch it. Moreover, I am not interested in the content of news. The internet is instant, whenever I want to see, I can see and read them. You don't have to open it in a specific time. The news is available on the internet before traditional media..." (Male Participant-M.) 
"Getting information is faster. We can get much more intensive information. The information is much current. Information can change instantly. We can be informed about the events, organizations by social media, such as concerts or festivals..."(female participant-Z.)

"Every day, I look it absolutely. What is going on... It is a kind of getting information briefly. Because you can not write on more. In a short time, I have a chance to learn what is happening, what happened...'(female participant-D.)

"Before I enter the news site, the first platform to see is Twitter, because the true information, the true information is on it thanks to the channels which I follow..." ( Male Participant-S.)

\section{- Relational / Socialization use:}

When it is examined the social networking sites usage of people for relational or socialization purposes, it can be seen that the same purposes with face-to-face interpersonal communication are satisfied on the online environment. It has been determined that people use social networking sites to meet/stay friends, to make new friends, to start or maintain emotional relationships, to meet with their distant friends, to learn social activities, to come together with common interests and to share them. Participants' responses support that people who are particularly introverted personality or who do not like to talk too much have an opportunity to relate and socialize. It is also emphasized that there is no other possibility of being together with friends who are in different places at the same time. In this sense, some of the answers given by the participants are below.

"For example, recently we organized meeting for a reunion. And I saw my friends, who I could not see for five or six years. If the social platforms like Facebook and Twitter had not arisen, it would be harder to establish a dialogue. What are they doing, what aren't they doing... we would have to start from the beginning..." (female participant-D.)

"With close people to me, of course, we choose face to face communication first, but we also talk by using social media. With relatives who live far away, we communicate through social media. So our communication between distant relations can be more. As a new excitement, people want to be more socialized in that platforms. (Male participant-S.)

"We can get in touch on Facebook with our friends who are living away from us. When we write a message on Facebook, it stays there that my friend can answer whenever he/she wants 
or we can have new friends on social media platforms. According to me, it is a positive development for our relationships..."(male participant-Mehmet)

"I am using social media mostly for following my friends to learn what they are doing, being informed about them. Because I don't have phone numbers all of my friends... So I use it only for communicating...' (male participant-G.)

\section{- Expressive uses are:}

It is of utmost importance that people can actualize the expression feature in terms of interpersonal communication both in face-to-face communication and in internal communication. In this sense, participants' responses show that social network sites are highly effective in both communicating with people and sharing internal expressions. It is also stated that they are able to express themselves in communication with other people, to share information about themselves, especially to explain their feelings, to express their feelings more easily than in everyday life. Nevertheless, in everyday life, it is often the expressions which can not be given in face-to-face communication or the unexpressed emotions or thoughts can be expressed quite comfortable in sharing on social network sites. In this sense, some of the answers given by the participants are stated below.

"It is a kind of public speaker for our opinions and wishes. Before social media, we were not able to mention/tell our opinions and wishes. We could not transfer to society. We could only tell to our friends. The people who could address to society, were only columnists, writers, journalists and opinion leaders. But now, with the emerging of social media, I can express myself to a thousand and five hundred people quickly. If they like my sharings, they can also share it, so maybe the effect of it reach a million people. It is a kind of nice thing.' (Male participant-M.)

"If I think personally, I like to write or tell my psychological, spiritual changings to social media. A song or poetry can identify my feelings. Moreover, recently I am doing most of the time that 'this song is playing inside of me.' So it reflects my feelings. On the other hand, I use Twitter for expressing my thoughts or feelings for anybody or anything, for example, If I am angry with somebody, I can write to Twitter..."(female participant-D.) 
"Actually I can say that social media helps me to clarify myself more truly things that I share and I like, helps me to express myself more clear. Thanks to this, people can learn new and unknown things about me."(Male participant-S.)

"When I go to a new place, I want to share my happiness with others. Social media allows me to share my feelings and thoughts. I can say that I go there it was beautiful. Also, I can share photos of that place. So people can see my advice. On the other hand, if I am angry about something, there is a place that I can express myself anymore..."(female participant-Z.)

\section{- Strategic uses are:}

Facial interpersonal communication requires people to share the same venue, which is possible through participation in some events. People can be informed about these events through social networking sites, and they can inform and invite other people. At the same time, they are able to follow trends/news and get information about topics they are interested. However, it is possible to be continuously informed about the information flow by creating a group related to an event. At the same time, it is possible to reach to the participants of an organized activity quickly and become active. Another important point that the participants have noted is that it is possible to have all the information about it, even if they do not participate in the event. In this sense, some of the answers given by the participants are stated at the below.

"We organized our meetings on Facebook, we could come together thanks to it. For example, I am a member of Foundation of Aegean Forest. I can follow the foundations which I belong to on Facebook. I can be informed about them. When they organize a meeting or an event, we can reach information. We can organize an activity entirely in this way. I can join or not, I can reply there surely. Before now, it was really hard; we could not take response quickly. “(Female participant-S.)

"Social media makes usage easier and convenient thanks to its structure. Especially, as I mentioned before, the meetings, announcements, events can be shared, and the facilities for implementing questionnaire is very good for obtaining data. That's why I am using it actively.”(Male participant-S.) 
"When there is a change in the meeting place or date and time, I am announcing it on social media. So I use everything which I use in interpersonal communication also on social media. Without struggling, I can get most of the things also I can save time.( Male participant, G. )

"I use the social media platforms for organizations. Also, I can share my location information by using google maps or for reaching a place. On the networks, we can be organized..."(Male participant-M.

\section{Conclusion}

Along with the development of Web 2.0 technology, the social network site has caused changes in traditional communication and social structure for people. Social networking sites have emerged as a new area of communication and socialization. While these influences primarily affect young people, social network sites are now considered social interaction areas for all people. Social network sites meet the needs of a large number of people, such as having education, researching, chatting, maintaining old friendships and making new friendships, etc. thanks to its features that already have and developing every passing day. For this reason, social network sites may not be able to replace face-to-face communication for many people; But it can be said that it has reached an indispensable position. For this reason, Erlin and Arita Fitri (2015) point out that in their research findings, the students spend about 30-59 minutes each day on social network sites (Facebook), and explaining that they have entered Facebook many times in one day. Oloo (2013) wants to draw attention to the fact that this time is much more than this and as a result of his survey, participants reported that they spent about 2-4 hours during the day on social network sites.

The purpose of this study is to determine what people use social network sites for and what personal communication purposes they aim. At the same time, it is desirable to make an assessment within the framework of uses and satisfaction theory as there is the purpose of satisfying the specific needs of the users. For this purpose, depth interviewing was conducted within the scope of MASA (Media Use as Social Action) dimensions. In general, the results of the research can be expressed as the use of the four dimensions of the MASA for informational-cooperative, relational-socialization, expressive, strategic purposes. The most striking result of the research is that the interpersonal communication that people establish with others has shifted from face-to-face to online. At this point, participants find this 
medium as effective and necessary with the aim of persisting or continuing their communication with both their near and far friends.

Whiting and Williams (2013) conducted a research for finding out the aims of the people for using social network sites that the results of research is $88 \%$ of social interaction, $80 \%$ information seeking, $76 \%$ pass time, $64 \%$ entertainment, $60 \%$ relaxation, $56 \%$ communicator utility, 56\% expression of opinions, $\% 52$ convenience utility, $\% 40$ information sharing, $\% 20$ surveillance and watching others. The result of this research also shows that it is used for social interaction at the highest level. Besides, Raacke and Bonds-Raacke (2008) found that as a result of research into student-related activities to discover Friend-Networking Sites, it was determined that $87.1 \%$ of the participants use social network sites as friend-networking. In this study, participants stated that even if they have used all the four dimensions, they have used Informational-cooperative and expressive dimensions more. At the same time, expressive dimension supports the process of interpersonal communication and inner communication with its weighted use because it facilitates the expression of what they will not or can not express in face-to-face communication.

Another result of research is related to the use of social network sites for strategic purposes. People can do what they want to do and enjoy the entertainment without being in the same space. In the same way, Spiliotopoulos et al. (2013) mean that people can meet their contribution, discovery, social interaction and entertainment needs through Facebook groups. Participants add that they can express themselves better in social network sites, and even explain their feelings and thoughts, which they can not do this in everyday life for many reasons. Quan-Haase and Young (2010) conclude that it is a very effective environment for "sharing problems and showing affection" and makes it easier to communicate with their partners about their problems. The research conducted by Mims et al. (2013) indicates that young people, who especially communicate through their social network sites (Facebook), do not have the opportunity to develop social relations in real life, but that they can be weak skills for interpersonal communication and interaction because they spend most of their time in this environment. Participants of the survey indicated that the social network sites meet the needs in the four dimensions but can not replace face-to-face communication. While realtime communication provided by face-to-face communication is considered to be more 
effective, that the environment is preferred for the reason of being able to stay in constant communication and facilitating follow-up.

When the results of research are evaluated in terms of Uses and Gratification theory which concerns on what people do with the media more than the effect of media on people, users of social network sites indicate that social network sites are characterized by informationalcooperative, relational-socialization, expressive, strategic, and four-dimensionality, but are responsive to the need for a large number of interpersonal communication. At this point, McGuire (1974) supports the expression that, social media creates more facilities for communication to people who are saturated in the meaning of the content. However, social networking sites allow people to share photos, comment, share information and links, it is also effective in meeting the daily needs of the people and in creating basic motivation (Quan-Haase and Young, 2010). At the same time, when research data is evaluated, it is revealed that participants have enough features to meet a large part of their interpersonal communication needs with their social network sites, in fact enough to reach satiation. At this level, compared to traditional media, social network sites ensure more satisfaction to people (Perse \& Courtright, 1993), participants are now associated with being "every consumer is a producer" in the expression of Levinson (2009), and it is quite decisive for having more satisfaction for future research, it will be useful to evaluate the relationship between the use of social network sites and relationship satisfaction, and what needs will be fulfilled in terms of interpersonal communication and internal communication. 


\section{References}

Al-Khaddam, H.K. (2013). Impact of Social Networks on Interpersonal Communication of the Students University College Irbid Girls: Facebook as a Model, Cross-Cultural Communication, Vol.9, No.5, 17-22.

Antheunis, M.L, Valkenburg, P.M.\& Peter, J. (2008). Getting Acquainted through Social Network Sites: Testing a Model of Online Uncertainty Reduction and Social Attraction, Amsterdam School of Communications Research, University of Amsterdam.

Bachrach, Y. , Kosinski, M. , Graepel, T. , Kohli, P. and Stillwell, D. (2012). Personality and Patterns of Facebook Usage, Web Science's 12, June22-24, 2012, Evanston, USA.

Bala, K.(2014). Social Media and Changing Communication Patterns, Global Media Journal-Indian Edition, 5 (1), 1-6.

Bandura, A. (2001). Social cognitive theory of mass communication, Media Psychology, 3 (3), 265-299.

Bateman, P.J, Pike, J.C. \& Butler, B.S.(2011). To disclose or not: publicness in social networking sites, Information Technology \& People, Vol. 24 No. 1, 78-100.

Beitzel, B. (2012). Information-Processing Theory for Classroom Teachers, OpenStax-CNX modüle, m42774, www.4.ncsu.edu/.../Cognitive\%20Psychology\%20Notes.pdf.

Blumler, J. G. , \& Katz, E. (Eds.). (1974). The uses of mass communications: Current perspectives on gratifications research. Beverly Hills, CA: SAGE Publications.

Boyce, C. \& Palena, N. (2006). Conducting In-Depth Interviews: A Guide for Designing and Conducting In-Depth Interviews for Evaluation Input. Watertown: Pathfinder International. Erişim Adresi: 19/09/2016 tarihinde http://www2.pathfinder.org/site/DocServer/m_e_tool_series_indepth_interviews.pdf adresinden erişilmiştir.

Boyd, D.M. and Ellison, N.B. (2008). Social Network Sites: Definition, History, and Scholarship. Journal of Computer-Mediated Communication, 13(1), 210-230.

Brandtzæg, P. B. (2012). Social networking sites: Their users and social implications - A longitudinal study. Journal of Computer-Mediated Communication, 17 (4), 467-488. Bryant, J. \& Oliver, M.B. (2008). Media Effects: Advances in Theory and Research, New York- London: Routledge, Taylor\& Francis Group.

Castells, M. (2010). The rise of network society, Chicester, England: Wiley-Blackwell. 
Collin, P. , Rahilly, K.; Richardson, I.and Third, A. (2011). The Benefits of Social Networking Services: A literatüre review. Cooperative Research Centre for Young People, Technology and Wellbeing. Melbourne.

Dijk van, J. (2006). The network society, Social aspects of new media. London, Thousans Oaks, New Delhi: Sage Publications.

Eke, H. N. , Omekwu, C. O. and Odoh, J. N. , (2014). The use of Social Networking Sites among the Undergraduate Students of University of Nigeria, Nsukka. Library Philosophy and Practice (e-journal), 1195.

Ellison, N. B. , Steinfield, C. , \& Lampe, C. (2007). The benefits of Facebook "friends": Social capital and college students' use of online social network sites. Journal of Computer Mediated Communication, 12(4), 1143-1168.

Ellison, N. B. \& Boyd. D. (2013). Sociality through Social Network Sites. In Dutton, W.H. (Ed.) The Oxford Handbook of Internet Studies. Oxford: Oxford University Press.

Erlin, T. \& Arita Fitri, S. (2015). Using Social Networks: Facebook Usage at the Riau College Students, Procedia Computer Science, 59, 559-566.

Flaherty, L. M. , Pearce, K. J. \& Rubin, R. B. (1998). Internet and face-to-face communication: Not functional alternatives, Communication Quarterly, 46(3), 250268.

Gudykunst, W. B. (1985). A Model of Uncertainty Reduction in Intercultural Encounters, Journal of Language and Social Psychology, Vol 4, Issue 2, 79-98.

Henson, B., Reyns, B. W. \& Fisher, B.S.(2011). Security in the 21st Century Examining the Link Between Online Social Network Activity, Privacy, and Interpersonal Victimization, Criminal Justice Review, 36(3), 253-268.

Houghton, D. J. (2012) The effects of day-to-day interaction via social network sites on interpersonal relationships, A thesis submitted for the degree of Doctor of Philosphy, University of Bath, School of Management, England.

Joinson, A. N. (2008). "Looking at", "Looking up" or "Keeping up with” People? Motives and Uses of Facebook, CHI 2008 Proceedings • Online Social Networks, April 5-10, Florence, Italy.

Junco, R. (2011). The relationship between frequency of Facebook use, participation in Facebook activities, and student engagement, Computers \& Education, 58, 162-171.

Kaplan, A. M. \& Haenlein, M. (2010). Users of the World, unite! The challenges and opportunities of social media, Business Horizons, 53 (1), 59-68. 
Katz, E., Blumler, J.G., Gurevitch, M. (1974). Uses and Gratifications Research. The Public Opinion Quarterly, Winter.

Lee, A. J. (2004). Effects of Visual Representation on Social Influence in Computer Mediated Communication Experimental Tests of the Social Identity Model of Deindividuation Effects, Human Communication Research, 30 (2), 234-259.

Levinson, P. (2009). New New Media, Boston: Ally\&Bacon.

Li, D.C. (2011). Online social network acceptance: a social perspective. Internet Research, 21(5), 562-580.

Mazman, S. G. \& Usluel, Y. K. (2011). Gender Differences in Using Social Networks, TOJET: The Turkish Online Journal of Educational Technology, 10 (2), 133-139.

McGuire, W. J. (1974). Psychological motives and communication gratification, In J. G. Blumler \& E. Katz (Eds.), The uses of mass communications: Current perspectives on gratifications research. Beverly Hills, CA: Sage Publications.

McLuhan, M. (2016). Understanding Media, The extensions of man, CreateSpace Independent Publishing Platform.

Mims, A. B. , Llanes, L. L. \& Didona, T. (2013). An Investigation into Facebook and its Relationship with Interpersonal Skills. The 2013 WEI International Academic Conference Proceedings, Orland1, USA.

Mustafa, S. E. \& Hamzah, A. (2011).Online Social Networking: A New Form of Social Interaction, International Journal of Social Science and Humanity, Vol. 1. No.2, 96-104.

Ngcongo, L. C. (2016). The Uses and Gratifications of Social Media, Baccalaureus Technologiae: Public Relations Management, Department of Integrated Communications Faculty of Humanities, Tshwane University of Technology.

Oloo, F. L. (2013). “Instagratification”: Uses and Gratification of Instagram by University Students for Interpersonal Communication. Masters of Arts Thesis in Communication and Media Studies, Eastern Mediterranean University, Gazimağusa, North Cyrprus.

Parks, M. R. \& Floyd, K. (1996). Making Friends in Cyberspace. Journal of Communication, 46 (1), 80-97.

Perse, E. M. \& Courtright, J. A. (1993). Normative Images of Communication Media: Mass and Interpersonal Channels in the New Mediated Environment. Human Communication Research, (19)4, 485-503. 
Petric, G. , Petrovcic, A. \& Vehovar, V. (2011). Social uses of interpersonal communication technologies in a complex media environment. European Journal of Communication, 26(2), 116-132.

Quan-Haase, A. \& Young, A. L. (2010). Uses and gratifications of social media: A comparison of Facebook and instant messaging. Bulletin of Science, Technology and Society, 30 (5), 350-361.

Raacke, J. \& Bonds-Raacke, J. (2008). MySpace and Facebook: Applying the Uses and Gratifications Theory to Exploring Friend-Networking Sites, CyberPsychology\&Behavior, 11 (2).

Ramirez, A. , Dimmick, J. , Feaster, J. , \& Lin, S. F. (2008). Revisiting interpersonal media competition: The gratification niches of instant messaging, e-mail, and the telephone. Communication Research, 35, 529-547. Renckstorf, K., McQuail, D. and Jankowski, N. (eds) (1996). Media Use as Social Action: A European Approach to Audience Studies. London: John Libbey.

Rheingold, H. (1993). The virtual community : homesteading on the electronic frontier. Reading, Mass.: Addison-Wesley Pub.

Spiliotopoulos, T. , Karnik, M. , Oakley, I. , Venkanathan, J. \& Nisi, V. (2013). Towards Understanding Social Media: Two Studies Exploring the Uses and Gratifications of Facebook, Proceedings of HCI, Korea.

Stafford, T. F. , Stafford, M. R. , \& Schkade, L. L. (2008). Determining uses and gratifications for the internet, Decision Sciences, 35, 259-288.

Tekin, H. H. (2006). Nitel Araştırma Yönteminin Bir Veri Toplama Tekniği Olarak Derinlemesine Görüşme, Sosyoloji Dergisi, 3(13), 101-116.

Thelwall, M. (2009). Social network sites: Users and uses. In: M. Zelkowitz (Ed.), Advances in Computers, 76. Elseveir: Amsterdam, pp. 19-73.

Valenzuela, S. , Park, N. \& Kee, K. F. (2009). Is There Social Capital in Social Network Site?: Facebook Use and College Students' Life Satisfaction, Trust, and Participation. Journal of Computer-Mediated Communication, 14, 875-901.

Westerman, D. , Van Der, H. K. \& Walther, J. B. (2008). How do people really seek information about others? Information seeking across Internet and traditional communication channels. Journal of Computer-Mediated Communication, 13, 751767. 
Whiting, A. \& Williams, D. (2013). Why people use social media: a uses and gratifications approach. Qualitative Market Research: An International Journal, 16(4), 362-369.

Wittel, A. (2001). Towards a network sociality. Theory, Culture and Society, 18, 31-50.

Zeitel-Bank, N. \& Tat, U. (June 2014). Social Media and Its Effects on Individuals and Social Systems, Human Capital without Borders: Knowledge and Learning for Quality of Life Management, Knowledge and Learning, International Conference, 25-27 June, 2014, Portoroz, Slovenia.

Zhao, S. (2006). Do Internet Users Have More Social Ties? A Call for Differentiated Analyses of Internet Use. Journal of Computer-Mediated Communication, 11, 844862. 